\title{
The relationship between serum hepatitis B core- related antigen and hepatitis $B$ virus DNA in treatment-naïve patients with hepatitis B cirrhosis: A cross-sectional study
}

\section{Baiguo Xu}

The Third Central Clinical College of Tianjin Medical University

\section{Lian Jia}

the Third Central Clinical College of Tianjin Medical University

Anjing Liu

Tanggu infectious disease hospital of Tianjin

\section{Ying Liu}

The Third Central Clinical College of Tianjin Medical University

\section{Tao Han}

The Third Central Clinical College of Tianjin Medical University

\section{Hua Guo}

The Third Central Clinical College of Tianjin Medical University

\section{Xian Ding}

The Third Central Clinical College of Tianjin Medical University

\section{Weili Yin}

the Third Central Clinical College of Tianjin Medical University

Hui-ling Xiang ( $\sim$ huilingxiang@163.com )

The Third Central Clinical College of Tianjin Medical University

\section{Research Article}

Keywords: Liver cirrhosis, hepatocellular, carcinoma, hepatitis B virus

Posted Date: November 15th, 2021

DOI: https://doi.org/10.21203/rs.3.rs-156751/v2

License: (1) This work is licensed under a Creative Commons Attribution 4.0 International License. Read Full License 


\section{Abstract}

Aims. The relationship between hepatitis B core-related antigen ( $\mathrm{HBcrAg}$ ) and hepatitis B virus (HBV) DNA has already been adequately researched in patients with chronic hepatitis $B(\mathrm{CHB})$ infection, but there are only a few researches yet on the correlations between HBcrAg and HBV DNA in treatment-naïve patients with hepatitis B cirrhosis. Here we explore the correlation between HBcrAg and HBV DNA in this population.

Methods. Available data and samples of 98 untreated patients with hepatitis B cirrhosis between October 2018 and October 2019 were analysed. Statistical analyses included baseline characteristics, univariate analysis, stratification analysis, three different analytical models, and a generalized additive model.

Results. After adjusting for all recorded confounders (sex, age, diagnosis of primary hepatic carcinoma, total bilirubin $\triangle \mathrm{TBIL} \otimes$, hepatitis B surface antigen ( $\mathrm{HBsAg}$ ), hepatitis B e antigen( $\mathrm{HBeAg})$, Child-Pugh class, family history of HBV infection, family history of hepatocellular carcinoma(HCC), alcohol-related liver disease (ALD), and diabetes mellitus), a linear relationship was detected between HBcrAg and HBV DNA $(\beta=0.59,95 \% \mathrm{Cl}=0.34-0.84, \mathrm{P}<0.0001)$. The variational trend of HBcrAg and HBV DNA in each stratified variable (sex, age, HBeAg, family history of HBV infection, family history of HCC, diabetes mellitus, diagnosis of primary hepatic carcinoma, Child-Pugh class, and ALD) were consistent.

Conclusion. There was a linear and positive correlation between HBcrAg and HBV DNA in treatment-naïve patients with hepatitis B cirrhosis.

\section{Introduction}

Hepatitis B virus (HBV) infection is a major global problem; in 2010, about 248 million people were chronically infected with HBV worldwide [1]. Around $8-20 \%$ of patients with chronic hepatitis B (CHB) develop cirrhosis within five years, with about $10-17 \%$ develop hepatocellular carcinoma (HCC) within the same time frame [2]. The use of powerful anti-HBV agents can decrease the rate of HCC, but not prevent the incidence of HCC, primarily because intrahepatic covalently closed circular DNA (cccDNA) is not wholly removed from the liver cell nuclei[3-5]. Because testing for intrahepatic cccDNA involves an invasive procedure, and it is challenging to implement in routine clinical practice. Non-invasive serological markers can be used as alternative markers for viral replication activity in the liver, including serum HBV DNA levels and serum hepatitis B surface antigen (HBsAg) titers[6-9]. Hepatitis B virus core-related antigen ( $\mathrm{HBcrAg}$ ), a serological marker, has been widely confirmed to be associated with serum HBV DNA and intrahepatic cccDNA in patients with $\mathrm{CHB}$ [10-16]. Few studies have been conducted on the correlation between serum HBcrAg and HBV DNA in treatment-naïve patients with hepatitis B cirrhosis. Understanding this correlation could facilitate further development of HBcrAg as a noninvasive marker for serological monitoring in patients with treatment-naïve hepatitis B cirrhosis. The predictive models of the progression of hepatitis B cirrhosis have been hotspots in recent years. HBcrAg and HBV DNA had already been used as predictors of the progression of hepatitis B cirrhosis. However, the precondition of 
establishing a reliable predictive model is to make the correlation between predictors clear. Here, we explore the relationship between serum HBcrAg and serum HBV DNA in treatment-naïve patients with cirrhosis.

\section{Materials And Methods}

\section{Participant selection}

This is a retrospective study including only treatment-naïve patients with hepatitis B cirrhosis who were hospitalized at our hospital from October 2018 to October 2019. Participants with hepatitis $\mathrm{C}$ or human immunodeficiency virus co-infection and those missing virological data were excluded from our analyses, as were those without surplus serum samples for HBcrAg measurement or whose serum samples did not stored at $-20^{\circ} \mathrm{C}$ until analysis. However, patients with alcohol-related liver disease (ALD) or diabetes mellitus were not excluded. Detailed information on patient acquisition procedures presented in Figure 1.

\section{Ethics approval statement}

This project was performed in concordance with the Declaration of Helsinki. Retrospective testing of stored clinical surplus samples was approved by the medical ethics committee of our hospital on September 1st, 2018. Informed consent was obtained from each patient. All data was analysed anonymously.

\section{HBV serological markers}

HBsAg and HBeAg quantification

HBsAg levels were quantified by the Abbott ARCHITECT i4000SR chemiluminescent microparticle immunoassay (Abbott Diagnostics.; Abbott Park, IL, USA), with a detection range from 0.05 to 250.00 $\mathrm{IU} / \mathrm{mL}$. Samples that had a concentration of more than $250.00 \mathrm{IU} / \mathrm{mL}$ were diluted and retested. $\mathrm{HBeAg}$ levels were detected using commercially available enzyme immunoassay kits (Abbott Diagnostics.; Abbott Park, IL, USA).

\section{HBV-DNA quantification}

Serum HBV-DNA was quantified using real-time PCR HBV assay, performed on Anadas9850 (Amplly Engineering co. Ltd.; Xiamen, CN), a fully automated nucleic acid extraction and real-time PCR system. The limit of detection (LOD) was $\sim 20.00 \mathrm{IU} / \mathrm{mL}$. Quantified samples with a concentration of more than $5.00 \times 10^{8} \mathrm{IU} / \mathrm{mL}$ were diluted and retested, while samples with a concentration less than $20.00 \mathrm{IU} / \mathrm{mL}$ were regarded as undetectable.

\section{HBcrAg quantification}


Surplus serum samples were stored at $-20^{\circ} \mathrm{C}$ and tested using a fully automatic chemiluminescent enzyme immunoassay system (CLIA; Lumipulse G1200, Fujirebio.; Tokyo, Japan), according to the manufacturer's instructions. The assay provided a linear range of $3.00-7.00 \log _{10} \mathrm{U} / \mathrm{mL}$. However, the machine could detect levels lower than $3.00 \mathrm{log} \mathrm{U} / \mathrm{mL}$ down to $2.00 \mathrm{log} \mathrm{U} / \mathrm{mL}$ in HBcrAg-positive samples. HBcrAg levels below $2.00 \mathrm{log} \mathrm{U} / \mathrm{mL}$ were treated as $2.00 \mathrm{log} \mathrm{U} / \mathrm{mL}$ for statistical analysis. Samples with HBcrAg levels $>7.00 \log 10 \mathrm{U} / \mathrm{mL}$ were diluted with the serum of healthy controls and retested to quantify HBcrAg levels.

\section{Diagnosis of liver cirrhosis and primary liver cancer}

Cirrhosis diagnosed according to the Chinese Guidelines on the Management of Liver Cirrhosis (2019 version) released by the Chinese Society of Hepatology, Chinese Medical Association. The diagnosis of all the patients accorded to the guidelines for the diagnosis and treatment of primary hepatic carcinoma (2019 version) released by the National Health Commission and Hospital Administration of the People's Republic of China.

\section{Statistical analysis}

Measured levels of serum HBcrAg, HBsAg and HBV DNA were $\log _{10}$ transformed. Statistical analyses conducted in five steps. Patients divided into two groups according to HBeAg levels. First, we analyzed the baseline characteristics of patients according the Succeeding principles: (1) continuous variables were expressed as means \pm standard deviation (normal distribution) or medians (quartiles) (skewed distribution), and categorical variables were expressed as a frequency and/or as percentages; (2) oneway ANOVA, Kruskal-Wallis $\mathrm{H}$ test, and chi-square test were used to determine the significance of any discrepancy between the means and proportions of the groups. Second, a univariate linear regression model was used to evaluate the associations between HBcrAg and HBV DNA. Third, we showed the results of unadjusted, minimally adjusted analyses and fully adjusted analyses. When covariants added to this model, and the matched odds ratio changed by $\geq 10.00 \%$, the covariants were adjusted. Fourth, given that HBcrAg was a continuous variable, generalized additive models were used to identify whether the relationship with HBV DNA was linear or non-linear. Fifth, stratified linear regression models were used in subgroup analyses. Likelihood ratio tests were used to inspect the modifications and interactions of subgroups. All data were analyzed using the statistical packages R version 3.4.3 (R Foundation for Statistical Computing.; Vienna, Austria) and EmpowerStats (X\&Y Solutions, Inc.; Boston, MA, USA). $\mathrm{P}<0.05$ (two-sided) was considered to indicate statistical significance.

\section{Results}

\section{Baseline characteristics}

In this study, we analyzed 98 eligible treatment-naïve participants diagnosed with hepatitis B cirrhosis. All enrolled patients had positive HBV DNA status. The average age of all participants was $56.28 \pm 10.14$ years, and $81.63 \%$ were male. The mean of serum HBV DNA and serum HBcrAg levels were $4.94 \pm 1.55$ 
$\log _{10} \mathrm{U} / \mathrm{mL}$ and $5.67 \pm 1.51 \log _{10} \mathrm{U} / \mathrm{mL}$ after $\log _{10}$ transformation, respectively. Patients were divided into two groups according to HBeAg status in order to clarify the correlation between serum HBcrAg and HBV DNA. Baseline characteristics of the participants are presented in Table 1. There were no notable distinctions in sex, age , PLT, ALT, AST, TBIL, ALB, INR, HBV DNA, HBsAg, Child-Pugh class, diagnosis of primary hepatic carcinoma, family history of HBV infection, family history of HCC, ALD, and diabetes mellitus among $\mathrm{HBeAg}$ positive and negative groups. There were significant statistical differences in HBcrAg and family history of HBV infection among HBeAg positive and negative groups.

\section{Univariate analysis}

The univariate analysis results are presented in Table 2. Our data showed continuous variables, $\mathrm{HBcrAg}$, and HBsAg were positively correlated with HBV DNA levels. Whereas age, sex, ALT,PLT, ALB, AST, TBIL, INR, HBV DNA, Child-Pugh class, diagnosis of primary hepatic carcinoma, family history of HBV infection, family history of HCC, ALD, and diabetes mellitus were not correlated with HBV DNA levels in treatment-naïve patients diagnosed with hepatitis $B$ cirrhosis.

\section{Analysis of the correlation between HBcrAg and HBV DNA levels}

To clarify the correlation between serum HBcrAg and HBV DNA and its trend, participants were partitioned into three groups according to the value of HBcrAg, as follows: T1 (2.00-5.21 $\left.\log _{10} \mathrm{U} / \mathrm{mL}\right), \mathrm{T} 2$ (5.22-6.34 $\left.\log _{10} \mathrm{U} / \mathrm{mL}\right)$, and T3 (6.35-9.12 $\left.\log _{10} \mathrm{U} / \mathrm{mL}\right)$. The association between HBcrAg and HBV DNA was evaluated by a univariate linear regression model. The adjusted and non-adjusted models are shown in Table 3. In the crude model, HBcrAg was positively correlated with HBV DNA ( $\beta=0.53 ; 95 \%$ confidence interval $[\mathrm{Cl}]=0.35-0.70 ; \mathrm{P}<0.0001$ ), and the results using the preliminary adjusted model (adjusted only for age and sex) did not differ substantively $(\beta=0.53 ; 95 \% \mathrm{Cl}=0.36-0.71 ; \mathrm{P}<0.0001)$ Compared to the nonadjusted model. We also detected a clear association between HBcrAg and HBV DNA by using the adjusted model $\otimes(\beta=0.59 ; 95 \% \mathrm{Cl}=0.34-0.84 ; \mathrm{P}<0.0001)$, which adjusted for sex, age, diagnosis of primary hepatic carcinoma, TBIL, HBsAg, HBeAg, Child-Pugh class, family history of HCC, family history of HBV infection, ALD, and diabetes mellitus. In addition, we handled HBcrAg as a categorical variable (tripartition) for sensitivity analysis, and concluded that the variational trend was consistent between HBcrAg and HBV DNA across the three models, and the $p$ for trend was $<0.0001$.

\section{Analyses of linear relationships}

Given that HBcrAg was a continuous variable, we analyzed was there a linear or non-linear relationship between HBcrAg and HBV DNA. Our data concluded that the correlation between HBcrAg and HBV DNA was linear, by adjustment for sex, age, diagnosis of HCC, TBIL, HBsAg, HBeAg, Child-Pugh class, family history of HBV infection, family history of HCC, ALD, and diabetes mellitus (Fig. 2). Using a linear regression model, we calculated that the effect size, $95 \% \mathrm{Cl}$, and $\mathrm{P}$ value were $0.59,0.34-0.84$, and $<0.0001$, respectively (Table 4).

\section{Subgroup analyses and interactions among parameters}


The variational trends and significance of HBcrAg and HBV DNA in each stratified variable were consistent (including sex, age, HBeAg, family history of HBV infection and HCC, diagnosis of HCC, ALD, diabetes mellitus, and Child-Pugh class). Just as shown in Table 5, tests for interactions were not distinct for sex, age, HBeAg, family history of HBV infection, family history of HCC, diagnosis of HCC, ALD, diabetes mellitus, and Child-Pugh class (P-values for interaction are $0.42,0.87,0.06,0.30,0.85$, $0.63,0.81,0.68$, and 0.44 , respectively).

\section{Discussion}

HBcrAg, containing of three viral proteins (hepatitis B e antigen, HBV core antigen, and a small corerelated protein [p22cr]), is a novel serological marker of HBV replication[17], and it is superior to existing viral markers and its levels correlate well with intrahepatic cccDNA[10-16]. In the beginning report of $\mathrm{HBcrAg}$, Kimura et al. showed the level of HBcrAg varied with HBV DNA levels and suggested that HBcrAg analysis is a simple way to monitor patients with $\mathrm{CHB}$ [17]. In our study, we focused on the correlation between HBcrAg and HBV DNA in patients with hepatitis B cirrhosis.

Single-factor analysis presented that HBcrAg associated with HBV DNA significantly $(\beta=0.53$, $95 \% \mathrm{Cl}=0.35-0.70, p<0.0001$ ) in our study, which showed the effect size weaker than Loggi et al. reported, in which HBcrAg is closely related to HBV DNA in treatment-naïve patients with HBeAg negative[18]. The relationship between HBcrAg and HBV DNA in our study was weak to the latest research from a population of treatment-naïve patients with $\mathrm{CHB}$ that also found a tight correlation between $\mathrm{HBcrAg}$ and HBV DNA, regardless of HBeAg status and HBV genotype [19]. The likely reasons for these differences among studies may be because all subjects in our study were patients with cirrhosis, in whom more injury and repair occurred than in those with chronic infection and chronic hepatitis. As a result, the HBV DNA level decline with time was more pronounced in cirrhosis than CHB. However, genome-free HBV virions, which contained HBcAg, were reported to exist in Dane particles and p22cr [20], in which could assemble into Dane-like particles without HBV DNA [21]. Thus, the decline of HBcrAg level with time was tardive compared with that of HBV DNA.

The relationship between HBcrAg and HBV DNA may also be influenced by other viral serology parameters, liver function, family medical history of HBV infection or HCC, and other factors; therefore, adjusting confounders is important to lucubrate the accurate relationship between HBcrAg and HBV DNA. The result of multivariate logistic regression showed that HBcrAg correlated with HBV DNA levels clearly in either an unadjusted model or a fully adjusted model. Our results showed that a stable relationship between HBcrAg and HBV DNA was not affected by liver function, family history of HCC or HBV infection, and other serological virus markers. Testoni et al. found that HBcrAg levels correlated with serological HBV DNA levels in HBeAg positive and HBeAg nagtive patients with chronic hepatitis, but not in those with $\mathrm{HBeAg}(-)$ chronic infection[22]. We identified a stable correlation between HBcrAg and HBV DNA in treatment-naïve participants diagnosed with hepatitis $B$ cirrhosis, regardless of HBeAg status. Previous studies also demonstrated that HBcrAg directly reflects serological HBV DNA levels in CHB, in spite of HBeAgstatus[10, 12, 23-24]. 
Using HBcrAg as a continuous variable, we investigated whether it had a linear or non-linear relationship with HBV DNA level. After adjusting for all potential confounders, we identified a linear relationship between HBcrAg and HBV DNA under a generalized additive model $(\beta=0.59, P<0.0001)$. The linear correlation was independent of liver inflammation and other viral serological markers. The linear correlation was also well-established in patients with $\mathrm{CHB}$ [23]. Studies in Asia, and Europe concluded a close correlation of serological HBcrAg and serological HBV DNA levels in treatment-naïve patients with CHB $[10,14,25-26]$.

Subgroup analyses are crucial for scientific research[27], but most studies to date have only stratified according to HBeAg positive or negative status for subgroup analyses[25,28-30], and no interaction tests had conducted, preventing the exploration of the actual correlation between serological HBcrAg and serological HBV DNA. In this study, we used age, sex, HBeAg, family history of hepatitis B and HCC, diagnosis of HCC, ALD, diabetes mellitus, and Child-Pugh class as stratifying variables. The variational trends and significance of serological HBcrAg and serological HBV DNA in each stratified variable are consistent, indicating that the correlation between serological HBcrAg and serological HBV DNA was stable. No significant interaction effect on the relationship between serological HBcrAg and serological HBV DNA was identified, confirming the sound relationship between these two parameters. This was consistent with the research by Rokuhara et al., who also identified a linear correlation between serological HBcrAg and serological HBV DNA in CHB patients [23].The strong correlation between HBcrAg and HBV DNA reinforces the reliability of HBcrAg as an indicator of viral replication, consistent with previous findings in Asian populations [29]. Furthermore, the relationship between these parameters is also reflected in its utility for the judgment of the HBV DNA threshold. Yusuke et al. evaluated the accuracy of serological HBcrAg levels for diagnosis of three clinically significant HBV DNA thresholds. They showed that serum HBcrAg had high values for area under the receiver operating characteristic curve, sensitivity, and specificity [19]. As a serum marker, HBcrAg may preferably stratify the risk of patients who are intending to the cessation of NA [31]. HBcrAg is now proposed as a novel marker for treatment response monitoring and as an endpoint for clinical trials of anti-HBV agents aimed at a functional cure of HBV infection [12,31,32].

Our study has good qualities. Firstly, we used both a generalized linear model to evaluate the linear correlation between HBcrAg and HBV DNA and a generalized additive model to clarify whether there is a nonlinear relationship between these parameters. Secondly, this was an observational study, which included ineluctable potential confounders, therefore, we used rigorous statistical adjustment to reduce residual confounding. Although a previous resaech reported a linear association between HBcrAg and HBV DNA in CHB [23], the linear relationship in our study was shown to remain, even after adjustment for all potential confounders that were not adjusted in previous researches. Thirdly, the use of effect modifier factor analysis confirms the relationship between HBcrAg and HBV DNA; no interacting variables were found on the subgroup analysis.

This study also has some limitations. Firstly, this was an analytical cross-sectional study, which did not dynamically observe the corrlation between serological HBcrAg and serological HBV DNA. Secondly, as 
only Chinese participents were contained in the study and genotyping was not considered a stratified variable, the applicability of our conclusion to other ethnic groups is unknown. Thirdly, because of the limited availability of tissue from participants with cirrhosis, we could not investigate the correlation between HBcrAg and intrahepatic cccDNA in this population.

\section{Conclusions}

In summary, we identified a positive linear correlation between HBcrAg and HBV DNA in treatment-naïve patients with hepatitis $B$ cirrhosis. We showed that the correlation is not affected by sex, age, diagnosis of HCC, TBIL, HBsAg, HBeAg, Child-Pugh class, family history of hepatitis B and HCC, ALD, and diabetes mellitus. This study provides clinical data supporting the application of HBcrAg as a partial substitute for serological monitoring of HBV DNA in patients with hepatitis B cirrhosis. Making the correlation between $\mathrm{HBcrAg}$ and HBV DNA clear can help to establish a more reliable predictive model for the progression of hepatitis B cirrhosis patients.

\section{Declarations}

\section{Data Availability}

The data that related to the findings of our study are available on request from the corresponding author.

\section{Conflicts of Interest}

The authors declare that they have no conflicts of interest.

\section{References}

[1] Schweitzer A, Horn J, Mikolajczyk RT, et al. Estimations of worldwide prevalence of chronic hepatitis B virus infection: A systematic review of data published between 1965 and 2013. Lancet 2015; 386(10003):1546-55.

[2] Cornberg M, Protzer U, Petersen J, et al. Prophylaxis, diagnosis and therapy of hepatitis B virus infection the German guideline. Z Gastroenterol 2011; 49(7):871-930.

[3] Raimondo G, Allain JP, Brunetto MR, et al. Statements from the Taomina expert meeting on occult hepatitis B virus infection. J Hepatol 2008; 49(4):652-7.

[4] Brechot C, Thiers V, Kremsdorf D, et al. Persistent hepatitis B virus infection in subjects without hepatitis B surface antigen: Clinically significant or purely "occult"? J Hepatol 2001; 34:194-203.

[5] Bonilla GR, Roberts LR. The role of hepatitis B virus integrations in the pathogenesis of human hepatocellular carcinoma. J Hepatol 2005; 42:760-77. 
[6] Chen CJ, Yang HI, Su J, et al. Risk of hepatocellular carcinoma across a biological gradient of serum hepatitis B virus DNA level. JAMA 2006; 295:65-73.

[7] lloeje UH, Yang HI, Su J, et al. Predicting cirrhosis risk based on the level of circulating hepatitis B viral load. Gastroenterology 2006; 130:678-86.

[8] Tseng TC, Liu CJ, Yang HC, et al. Serum hepatitis B surface antigen levels help predict disease progression in patients with low hepatitis B virus loads. J Hepatol 2013; 57:441-50.

[9] Yuen MF, Wong DK, Fung J, et al. HBsAg Seroclearance in chronic hepatitis B in Asian patients: Replicative level and risk of hepatocellular carcinoma. Gastroenterology. 2008; 135:1192-9.

[10] Wong DK, Tanaka Y, Lai CL, Mizokami M, Fung J, Yuen MF. Hepatitis B virus core-related antigens as markers for monitoring chronic hepatitis B infection. J ClinMicrobiol 2007; 45:3942-7.

[11] Wong DK, Kopaniszen M, Seto W, et al. Reduction of hepatitis B core-related antigen by long term nucleoside nucleotide analogue therapy and its correlation with intrahepatic HBV DNA reduction. Hepatollnt 2015;9(S1):202.

[12] Wong DK, Seto WK, Cheung KS, et al. Hepatitis B virus core-related antigen as a surrogate marker for covalently closed circular DNA. Liver Int 2017; 37:995-1001.

[13] Liao H, Liu Y, Li X-d, et al. Correction: Monitoring of serum HBV RNA, HBcrAg, HBsAg and anti-HBc levels in patients during long-term nucleoside/nucleotide analogue therapy. AntivirTher 2019; 24:151-4.

[14] Suzuki F, Miyakoshi H, Kobayashi M, et al. Correlation between serum hepatitis B virus core-related antigen and intrahepatic covalently closed circular DNA in chronic hepatitis B patients. J Med Virol 2009; 81:27-33.

[15] Testoni B, Lebossé F, Scholtes C, et al. Serum hepatitis B core-related antigen (HBcrAg) correlates with covalently closed circular DNA transcriptional activity in chronic hepatitis B patients. J Hepatol 2019; 70:615-25.

[16] Chen EQ, Feng $S$, Wang ML, et al. Serum hepatitis B core-related antigen is a satisfactory surrogate marker of intrahepatic covalently closed circular DNA in chronic hepatitis B. Sci Rep 2017; 7(1):173.

[17] Kimura T, Rokuhara A, Sakamoto Y, et al. Sensitive enzyme immunoassay for hepatitis B virus corerelated antigens and their correlation to virus load. J ClinMicrobiol 2002; 40:439-45.

[18] Loggi E, Vukotic R, Conti F, et al. Serum hepatitis B core-related antigen is an effective tool to categorize patients with HBeAg-negative chronic hepatitis B. J Viral Hepat 2019;26(5):568-75.

[19] Shimakawa Y, Ndow G, Njie R, et al. Hepatitis B core-related antigen: An alternative to Hepatitis B virus DNA to assess treatment eligibility in Africa. Clin Infect Dis 2019; doi: 10.1093/cid/ciz412. 
[20] Ning X, Nguyen D, Mentzer L, et al. Secretion of genome-free hepatitis B virus-single strand blocking model for virion morphogenesis of para-retrovirus. PLoSPathog. 2011; 7(9):e1002255.

[21] Kimura T, Ohno N, Terada N, et al. Hepatitis B Virus DNA-negative dane particles lack core protein but contain a 22-kDa precore protein without C-terminal arginine-rich domain. J Biol Chem. 2005; 280(23):21713-9.

[22] Testoni B, Lebossé F, Scholtes $C$, et al. Serum hepatitis B core-related antigen (HBcrAg) correlates with covalently closed circular DNA transcriptional activity in chronic hepatitis B patients. J Hepatol 2019; 70:615-25.

[23] Rokuhara A, Tanaka E, Matsumoto A, et al. Clinical evaluation of a new enzyme immunoassay for hepatitis B virus core-related antigen; a marker distinct from viral DNA for monitoring lamivudine treatment. J Viral Hepat 2003; 10:324-30.

[24] Rokuhara A, Sun X, Tanaka E, et al. Hepatitis B virus core and core-related antigen quantitation in Chinese patients with chronic genotype B and C hepatitis B virus infection. J GastroenterolHepatol 2005; 20:1726-30.

[25] Maasoumy B, Wiegand SB, Jaroszewicz J, et al. Hepatitis B core-related antigen (HBcrAg) levels in the natural history of hepatitis $B$ virus infection in a large European cohort predominantly infected with genotypes A and D. ClinMicrobiol Infect 2015;21:606.e1-10.

[26] Riveiro-Barciela M, Bes M, Rodríguez-Frías F, et al. Serum hepatitis B core related antigen is more accurate than hepatitis $B$ surface antigen to identify inactive carriers, regardless of hepatitis $B$ virus genotype. ClinMicrobiol Infect 2017; 23:860-7.

[27] Vandenbroucke JP, von Elm E, Altman DG, Gotzsche PC, Mulrow CD, Pocock SJ, et al. Strengthening the reporting of observational studies in epidemiology (STROBE): Explanation and elaboration. PLoS Med 2007; 4:e297.

[28] Chen EQ, Wang ML, Tao YC, et al. Serum HBcrAg is better than HBV RNA and HBsAg in reflecting intrahepatic covalently closed circular DNA. J Viral Hepat 2019; 26(5):586-95.

[29] Seto W-K, Wong D K-H, Fung J, et al. Linearized hepatitis B surface antigen and hepatitis B corerelated antigen in the natural history of chronic hepatitis B ClinMicrobiol Infect 2014;20:1173-80.

[30] Rokuhara A, Sun X, Tanaka E, et al. Hepatitis B virus core and core-related antigen quantitation in Chinese patients with chronic genotype B and $C$ hepatitis B virus infection. J GastroenterolHepatol 2005:20(11):1726-30.

[31] Mak LY, Wong DK, Cheung KS, Seto WK, Lai CL, Yuen MF. Review article: Hepatitis B core-related antigen (HBcrAg): An emerging marker for chronic hepatitis B virus infection. Aliment PharmacolTher $2018 ; 47: 43-54$. 
[32] Seto WK, Lo YR, Pawlotsky JM, Yuen MF. Chronic hepatitis B virus infection. Lancet 2018; 392:231324.

\section{Tables}

Table 1.Baseline characteristics of participants according to HBeAg level $(\mathrm{N}=98)$ 


\begin{tabular}{|c|c|c|c|}
\hline \multirow[t]{2}{*}{ Characteristics } & \multicolumn{2}{|c|}{ HBeAg $(\log 10 \mathrm{U} / \mathrm{mL})$} & \multirow[t]{2}{*}{ P-value } \\
\hline & negative & positive & \\
\hline No. of participants & 49 & 49 & \\
\hline Age, mean \pm SD (years) & $56.69 \pm 8.20$ & $55.86 \pm 11.83$ & 0.69 \\
\hline Sex, n (\%) & & & 1.00 \\
\hline Male & $40(81.63 \%)$ & $40(81.63 \%)$ & \\
\hline Female & $9(18.37 \%)$ & $9(18.37 \%)$ & \\
\hline PLT $\times 10^{9} / \mathrm{L}$, median $(\mathrm{Q} 1-\mathrm{Q} 3)$ & $85.00(61.00-132.00)$ & $84.00(61.00-123.00)$ & 0.29 \\
\hline ALT U/L, median (Q1-Q3) & $35.00(26.00-70.00)$ & $38.00(28.00-115.00)$ & 0.81 \\
\hline AST U/L, median (Q1-Q3) & $60.00(40.00-102.00)$ & $63.00(44.00-162.00)$ & 0.50 \\
\hline TBIL $\mu \mathrm{mol} / \mathrm{L}$, median (Q1-Q3) & $21.90(13.80-44.60)$ & $35.20(19.60-63.70)$ & 0.84 \\
\hline $\mathrm{ALB} g / \mathrm{L}, \mathrm{mean} \pm \mathrm{SD}$ & $33.37 \pm 6.43$ & $33.83 \pm 5.80$ & 0.72 \\
\hline INR, mean \pm SD & $1.34 \pm 0.49$ & $1.40 \pm 0.41$ & 0.53 \\
\hline HBV DNA $\log 10 \mathrm{IU} / \mathrm{mL}$, mean $\pm \mathrm{SD}$ & $4.66 \pm 1.42$ & $5.22 \pm 1.64$ & 0.10 \\
\hline HBcrAg $\log 10 \mathrm{U} / \mathrm{mL}$, mean $\pm \mathrm{SD}$ & $4.80 \pm 1.43$ & $6.54 \pm 1.03$ & $<0.001$ \\
\hline HBsAg $\log 10 \mathrm{U} / \mathrm{mL}$, mean $\pm \mathrm{SD}$ & $2.85 \pm 0.91$ & $3.21 \pm 0.89$ & 0.05 \\
\hline Child-Pugh class, n (\%) & & & 0.09 \\
\hline A & $24(48.98 \%)$ & $14(28.57 \%)$ & \\
\hline B & $14(28.57 \%)$ & $23(46.94 \%)$ & \\
\hline $\mathrm{C}$ & $11(22.45 \%)$ & $12(24.49 \%)$ & \\
\hline Family history of HBV infection, n (\%) & & & 0.04 \\
\hline No & $32(65.31 \%)$ & $41(83.67 \%)$ & \\
\hline Yes & $17(34.69 \%)$ & $8(16.33 \%)$ & \\
\hline Family history of HCC, n (\%) & & & 0.29 \\
\hline No & $43(87.76 \%)$ & $46(93.88 \%)$ & \\
\hline Yes & 6 (12.24\%) & $3(6.12 \%)$ & \\
\hline ALD & & & 0.29 \\
\hline No & $29(59.18 \%)$ & $34(69.39 \%)$ & \\
\hline Yes & $20(40.82 \%)$ & $15(30.61 \%)$ & \\
\hline Diabetes mellitus, n (\%) & & & 1.00 \\
\hline No & $40(81.63 \%)$ & $40(81.63 \%)$ & \\
\hline Yes & $9(18.37 \%)$ & $9(18.37 \%)$ & \\
\hline Diagnosis of primary hepatic carcinoma & & & 0.11 \\
\hline No & $20(40.82 \%)$ & 28 (57.14\%) & - \\
\hline Yes & 29 (59.18\%) & 21 (42.86\%) & \\
\hline
\end{tabular}

Note 1: Data are presented as: mean $\pm \mathrm{SD}, \mathrm{n}(\%)$, median (Q1-Q3), andn (\%). 


\begin{abstract}
Abbreviations: HBeAg, hepatitis B e-antigen; PLT, platelet;ALT, alanine aminotransferase; AST, aspartate aminotransferase; TBIL, total bilirubin; ALB, albumin; INR, International Normalized Ratio; HBV DNA, hepatitis B virus deoxyribonucleic acid; HBcrAg, hepatitis B core-related antigen; HBsAg, hepatitis B surface antigen; HCC, hepatocellular carcinoma;ALD, alcoholic liver disease.
\end{abstract}

Table 2.Univariate analysis of HBV DNA $\left(\log _{10} \mathrm{IU} / \mathrm{mL}\right)$ 


\begin{tabular}{|c|c|c|c|}
\hline Covariates & Statistics & B $(95 \% \mathrm{CI})$ & P-value \\
\hline Age (years) & $56.28 \pm 10.14$ & $0.02(-0.03,0.03)$ & 0.92 \\
\hline \multicolumn{4}{|l|}{ Sex } \\
\hline Male & $80(81.63 \%)$ & Reference & \\
\hline Female & $18(18.37 \%)$ & $-0.06(-0.86,0.74)$ & 0.88 \\
\hline PLT×109/L, median (Q1- Q3) & $84.00(24.00-301.00)$ & $0.003(-0.003,0.008)$ & 0.32 \\
\hline ALT U/L, median (Q1-Q3) & $37.00(8.00-4356.00)$ & $-0.0001(-0.0007,0.0005)$ & 0.70 \\
\hline AST U/L, median (Q1-Q3) & $61.50(6.00-2784.00)$ & $-0.0003(-0.0011,0.0005)$ & 0.42 \\
\hline TBIL (mol/L) & $28.40(5.50-336.30)$ & $-0.004(-0.008,0.001)$ & 0.09 \\
\hline $\mathrm{ALB}(\mathrm{g} / \mathrm{L})$ & $33.60 \pm 6.09$ & $-0.01(-0.07,0.04)$ & 0.58 \\
\hline INR & $1.37 \pm 0.45$ & $-0.20(-0.89,0.49)$ & 0.57 \\
\hline HBcrAg $(\log 10 \mathrm{U} / \mathrm{mL})$ & $5.67 \pm 1.51$ & $0.53(0.35,0.70)$ & $<0.0001$ \\
\hline HBsAg (IU/mL) & $3.03 \pm 0.91$ & $0.49(0.16,0.82)$ & 0.01 \\
\hline \multicolumn{4}{|l|}{$\mathrm{HBeAg}$} \\
\hline Negative & $49(50.00 \%)$ & Reference & \\
\hline Positive & $49(50.00 \%)$ & $0.57(-0.04,1.18)$ & 0.07 \\
\hline \multicolumn{4}{|l|}{ Diagnosis of HCC } \\
\hline No & $48(48.98 \%)$ & Reference & \\
\hline Yes & $50(51.02 \%)$ & $-0.54(-1.14,0.07)$ & 0.09 \\
\hline \multicolumn{4}{|l|}{ Child-Pugh class } \\
\hline A & $38(38.78 \%)$ & Reference & \\
\hline B & 37 (37.76\%) & $-0.08(-0.78,0.61)$ & 0.81 \\
\hline C & $23(23.47 \%)$ & $-0.80(-1.60,-0.01)$ & 0.05 \\
\hline \multicolumn{4}{|l|}{ Family history of hepatitis B } \\
\hline No & $73(74.49 \%)$ & Reference & \\
\hline Yes & $25(25.51 \%)$ & $0.18(-0.52,0.89)$ & 0.61 \\
\hline \multicolumn{4}{|l|}{ Family history of HCC } \\
\hline No & $89(90.82 \%)$ & Reference & \\
\hline Yes & $9(9.18 \%)$ & $-0.67(-1.73,0.40)$ & 0.22 \\
\hline \multicolumn{4}{|l|}{ ALD } \\
\hline No & $63(64.29 \%)$ & Reference & \\
\hline Yes & $35(35.71 \%)$ & $-0.25(-0.89,0.40)$ & 0.45 \\
\hline \multicolumn{4}{|l|}{ Diabetes Mellitus } \\
\hline No & $80(81.63 \%)$ & Reference & \\
\hline Yes & $18(18.37 \%)$ & $-0.58(-1.37,0.21)$ & 0.15 \\
\hline
\end{tabular}

te: In univariate analysis of PLT, and TBIL, values for $\beta$ and $95 \% \mathrm{CI}$ were small; therefore, they ə displayed to three decimal places and AST/ALT, to four decimal places.

Abbreviations: HBV DNA, hepatitis B virus deoxyribonucleic acid; CI, confidence interval; PLT, platelet;ALT, alanine aminotransferase; AST, aspartate aminotransferase; TBIL, total bilirubin; 
ALB, albumin; INR, International Normalized Ratio; HBcrAg, hepatitis B core-related antigen; HBsAg, hepatitis B surface antigen; HBeAg, hepatitis B e-antigen; HCC, hepatocellular carcinoma;ALD, alcohol-related liver disease.

Table3. Relationship between HBcrAg and HBV DNA $\left(\log _{10} \mathrm{IU} / \mathrm{mL}\right)$ in different models

\begin{tabular}{|c|c|c|c|c|c|c|c|c|c|}
\hline \multirow[t]{3}{*}{ Variable } & \multicolumn{3}{|c|}{ Crude Model } & \multicolumn{3}{|c|}{ Model $\mathrm{u}$} & \multicolumn{3}{|c|}{ Model [ } \\
\hline & $\beta$ & $(95 \%$ & P-value & $\beta$ & $(95 \%$ & P-value & $\beta$ & $(95 \%$ & P-value \\
\hline & \multicolumn{3}{|l|}{$\mathrm{CI})$} & \multicolumn{3}{|l|}{$\mathrm{CI})$} & \multicolumn{3}{|l|}{ CI) } \\
\hline HBcrAg & 0.53 & $(0.35$ & $<0.0001$ & 0.53 & $(0.36$ & $<0.0001$ & 0.59 & $(0.34$ & $<0.0001$ \\
\hline$\left(\log _{10} \mathrm{IU} / \mathrm{ml}\right)$ & \multicolumn{3}{|l|}{$0.70)$} & \multicolumn{3}{|l|}{$0.71)$} & \multicolumn{3}{|l|}{$0.84)$} \\
\hline \multicolumn{10}{|l|}{ HBcrAg } \\
\hline \multicolumn{10}{|l|}{ (tripartite) } \\
\hline $\mathrm{T} 1(2.00-5.21)$ & \multicolumn{2}{|c|}{ Reference } & & \multicolumn{2}{|c|}{ Reference } & & \multicolumn{2}{|c|}{ Reference } & \\
\hline \multirow[t]{2}{*}{$\mathrm{T} 2(5.22-6.34)$} & \multicolumn{2}{|c|}{ 0.68(-0.01, } & 0.0557 & 0.70 & $(0.00$ & 0.05 & 0.55 & $(-0.26$ & 0.19 \\
\hline & \multicolumn{2}{|l|}{ 1.36) } & & \multicolumn{2}{|l|}{ 1.39) } & & \multicolumn{2}{|l|}{ 1.36) } & \\
\hline \multirow[t]{2}{*}{ T3(6.35-9.12) } & 1.65 & $(0.97$ & $<0.0001$ & 1.69 & $(1.00$ & $<0.0001$ & 1.77 & $(0.89$ & $<0.001$ \\
\hline & \multicolumn{3}{|l|}{ 2.33) } & \multicolumn{2}{|c|}{ 2.38) } & & \multicolumn{2}{|l|}{ 2.64) } & \\
\hline$P$ for trend & \multicolumn{2}{|c|}{$<0.0001$} & & \multicolumn{2}{|c|}{$<0.0001$} & & \multicolumn{2}{|c|}{$<0.001$} & \\
\hline
\end{tabular}

Model I was adjusted for sex, age.

Model II was adjusted for sex, age, diagnosis of primary hepatic carcinoma, TBIL, HBsAg, HBeAg, Child-Pugh class, family history of HBV infection, family history of HCC, ALD, diabetes mellitus.

Abbreviations: HBcrAg, hepatitis B core-related antigen; HBVDNA, hepatitis B virus deoxyribonucleic acid; CI, confidence interval; HCC, hepatocellular carcinoma; TBIL, total bilirubin; HBsAg, hepatitis B surface antigen; HBeAg, hepatitis B e-antigen; ALD, alcoholrelated liver disease.

Table 4.The relationship between HBcrAg $\left(\log _{10} \mathrm{IU} / \mathrm{mL}\right)$ and HBV DNA $\left(\log _{10} \mathrm{IU} / \mathrm{mL}\right)$ is $\operatorname{linear}$ (Piece-wise Linear Regression).

\begin{tabular}{ccc}
\hline Effect size ( $\boldsymbol{\beta})$ & $\mathbf{9 5 \square C I}$ & P value \\
\hline 0.59 & $(0.34,0.84)$ & $<0.0001$ \\
\hline
\end{tabular}

A nonlinear relationship between them was detected after adjusting for sex, age, diagnosis of primary hepatic carcinoma, TBIL, HBsAg, HBeAg, Child-Pugh, family history of HBV infection, family history of HCC, ALD, diabetes mellitus. 
Abbreviations: HBcrAg, hepatitis B core-related antigen; HBVDNA, hepatitis B virus deoxyribonucleic acid;

CI, confidence interval; HCC, hepatocellular carcinoma; TBIL, total bilirubin; HBsAg, hepatitis B surface antigen; HBeAg, hepatitis B e-antigen; ALD, alcohol-related liver disease.

Table5. Effect size of HBcrAg $\left(\log _{10} \mathrm{U} / \mathrm{mL}\right)$ on HBV DNA $\left(\log _{10} \mathrm{U} / \mathrm{mL}\right)$ in pre-specified and exploratory subgroups

\begin{tabular}{|c|c|c|c|c|}
\hline Characteristic & No. of participants, $r$ & $\beta(95 \% \mathrm{CI})$ & $P$-value & $P$ for interaction \\
\hline Sex & & & & 0.42 \\
\hline Male & 80 & $0.48(0.27,0.70)$ & $<0.0001$ & \\
\hline Female & 18 & $0.40(-0.14, .94)$ & 0.18 & \\
\hline Age (years) * & & & & 0.87 \\
\hline $25-51$ & 31 & $0.69(0.20,1.17)$ & 0.01 & \\
\hline $52-61$ & 34 & $0.51(0.19,0.83)$ & 0.01 & \\
\hline $62-79$ & 33 & $0.25(-0.09, .59)$ & 0.17 & \\
\hline HBeAg & & & & 0.06 \\
\hline Negative & 49 & $0.41(0.15,0.66)$ & $<0.01$ & \\
\hline Positive & 49 & $1.00(0.57,1.43)$ & $<0.0001$ & \\
\hline Family history of HBV infection & & & & 0.29 \\
\hline No & 73 & $0.56(0.32,0.80)$ & $<0.0001$ & \\
\hline Yes & 25 & $0.33(-0.11,0.77)$ & 0.17 & \\
\hline Family history of HCC & & & & 0.85 \\
\hline No & 89 & $0.53(0.33,0.73)$ & $<0.0001$ & \\
\hline Yes & 9 & - & - & \\
\hline Diagnosis of HCC & & & & 0.63 \\
\hline No & 48 & $0.55(0.23,0.86)$ & $<0.01$ & \\
\hline Yes & 50 & $0.32(0.06,0.57)$ & 0.02 & \\
\hline ALD & & & & 0.81 \\
\hline No & 63 & $0.49(0.24,0.75)$ & $<0.001$ & \\
\hline Yes & 35 & $0.48(0.03,0.92)$ & 0.05 & \\
\hline Diabetes mellitus & & & & 0.68 \\
\hline No & 80 & $0.47(0.23,0.72)$ & $<0.001$ & \\
\hline Yes & 18 & $0.61(0.12,1.10)$ & 0.04 & \\
\hline Child-Pugh class & & & & 0.43 \\
\hline A & 38 & $0.65(0.28,1.02)$ & $<0.001$ & \\
\hline B & 37 & $0.49(0.15,0.83)$ & 0.01 & \\
\hline C & 23 & $0.34(-0.14, .81)$ & 0.19 & \\
\hline
\end{tabular}

Note $1 *$ : When age is a stratified variable, age is not adjusted.

Adjusted for age, PLT, ALT, AST, TBIL, ALB, INR, HBsAg. 
Abbreviations: HBcrAg, hepatitis B core-related antigen; HBVDNA, hepatitis B virus deoxyribonucleic acid;

CI, confidence interval;HBeAg, hepatitis B e-antigen; HCC, hepatocellular carcinoma; ALD, alcoholic liver disease; PLT, platelet;ALT, alanine aminotransferase; AST, aspartate aminotransferase; TBIL, total bilirubin; ALB, albumin; INR, International Normalized Ratio; HBsAg, hepatitis B surface antigen.

\section{Abbreviations}

$H B V$, hepatitis B virus; $H B c r A g$, hepatitis B virus core-related antigen, $\mathrm{HBeAg}$, hepatitis $B$ e antigen; $\mathrm{HBsAg}$, hepatitis $B$ surface antigen; HBV DNA, hepatitis $B$ virus deoxyribonucleic acid; $C H B$, chronic hepatitis $B$; HCC, hepatocellular carcinoma; PLT, platelets; TBIL, total bilirubin; ALB, albumin; INR, International Normalized Ratio; ALD, alcohol-related liver disease; cccDNA, covalently closed circular DNA; NAs, nucleoside analogues.

\section{Figures}


Figure 1.

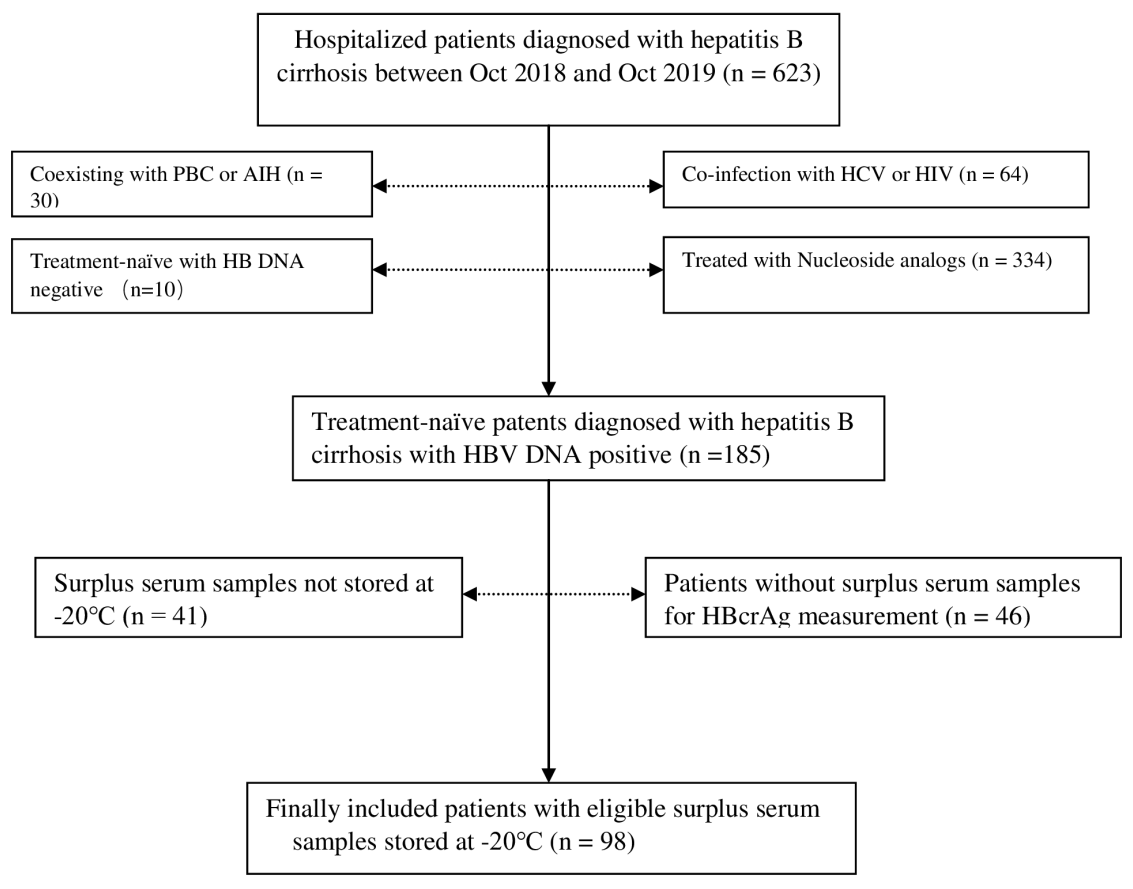

\section{Figure 1}

The acquisition process of patients with surplus serum samples included in this retrospective study. Abbreviations: HBV DNA, hepatitis B virus deoxyribonucleic acid, $\mathrm{PBC}$, primary biliary cirrhosis; $\mathrm{AlH}$, autoimmune hepatitis; HCV, hepatitis C virus; HIV, Human Immunodeficiency Virus, HBcrAg, hepatitis B core-related antigen. 
Figure 2

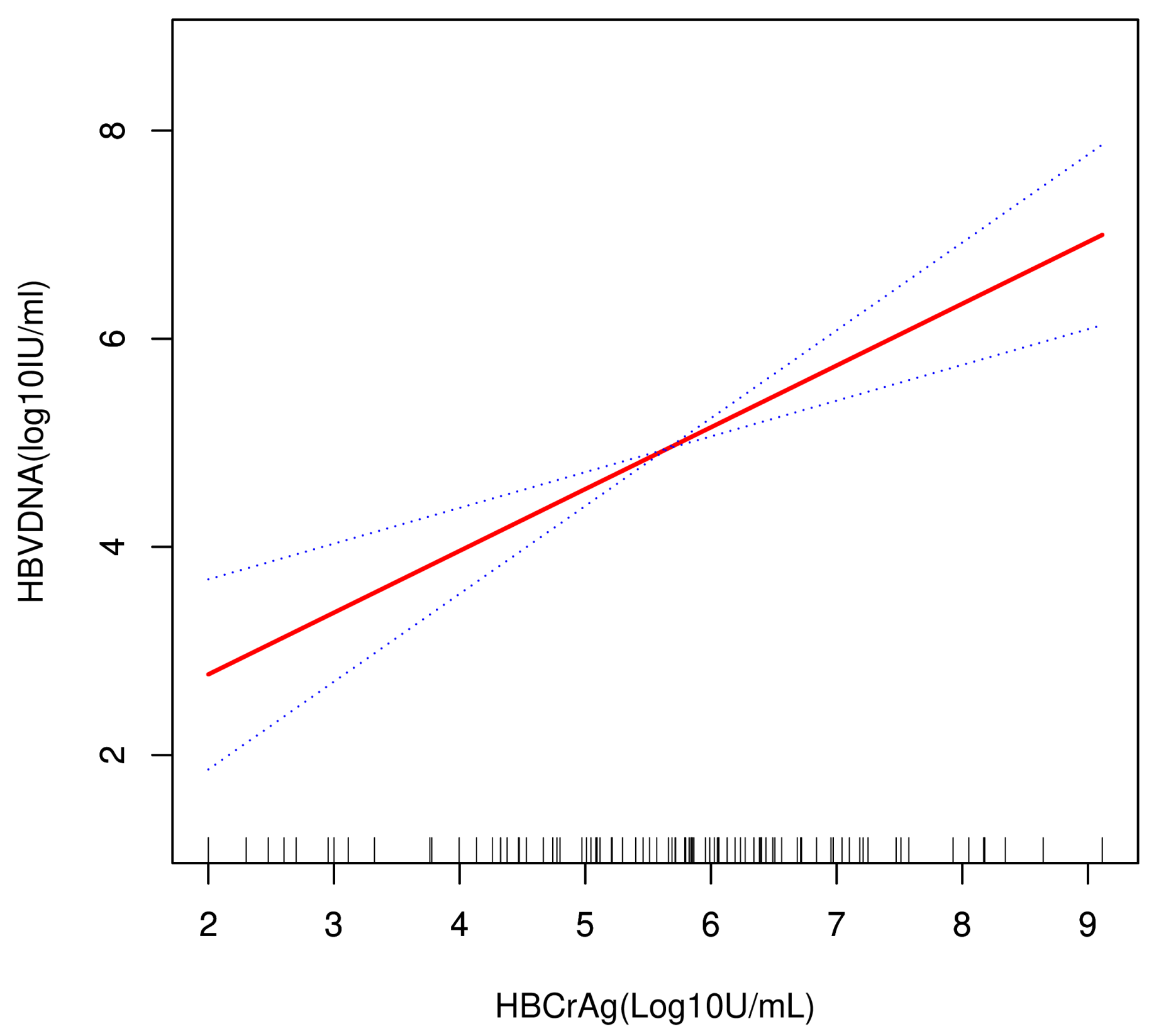

\section{Figure 2}

A linear association was found between HBcrAg $(\log 10 \mathrm{IU} / \mathrm{mL})$ and HBV DNA $(\log 10 \mathrm{IU} / \mathrm{mL})(P<0.01)$ using a generalized additive model (GAM). Note1: Solid red line: linear fit between variables. Blue bands: 95\% of confidence interval for the fit. Note2: Adjusted for sex, age, diagnosis of primary hepatic carcinoma, TBIL, HBsAg, HBeAg, Child-Pugh class, family history of hepatitis B, family history of HCC, ALD, diabetes. Abbreviations: $\mathrm{Cl}$, confidence interval; HBcrAg, hepatitis B core-related antigen; HBV DNA, 
HBeAg, hepatitis B e-antigen; hepatitis B virus deoxyribonucleic acid; HCC, hepatocellular carcinoma; HBsAg, hepatitis B surface antigen; ALD, alcoholic liver disease. 